\title{
Editorial
}

\section{Why does maintenance planning require a bespoke approach}

\author{
Journal of Building Appraisal (2009) 5, 1-5. doi:10.1057/jba.2009.18
}

\section{INTRODUCTION}

This editorial piece responds to yet another 'one spreadsheet fits all' maintenance regime, which was recently shown to the author. The author believes that maintenance planning to be properly effective should be a bespoke operation. Unless there are a number of identical buildings of a similar age, used for similar purposes by users with similar commercial outlooks, then while any maintenance plan is probably better than none what so ever, such a one size fits all approach is unlikely to deliver a truly effective maintenance plan, which meets the needs of the building, the commercial operation and the operator.

Maintenance can be described as work necessary to keep or restore every component of a building to an acceptable standard for an acceptable cost. Maintenance is also about the administrative and technical functions required to ensure a building continues to perform its required function to a satisfactory level. In terms of the total life cycle cost of a building, maintenance costs would generally greatly outweigh procurement and construction costs by a considerable margin. That margin will widen the longer the building remains in use. Maintenance is however often not seen as a high priority by building owners, the benefits not being readily quantifiable, and as such can be one of the first operations to feel the effects of any cuts in the operational budget. The wisdom of such action falls outside the remit of this piece.

\section{CATEGORIES OF MAINTENANCE}

The events that give rise to maintenance requirements are varied, and any plan must reflect that fact. Broadly speaking, maintenance tasks can be undertaken in one of two categories. The first is as a reaction to an event (Figure 1), that is, a window is broken and a glazier is engaged to effect repairs. The other category of maintenance would seek to predict maintenance requirements and undertake the work, either by remedial maintenance or replacement, before a total failure or an unacceptable reduction in performance occurs (Figures 2 and 3), that is, timber window frames are periodically primed and re-painted before solar action to the paintwork exposes the wood to decay, thus requiring an entire window replacement. It is this second category of predictive maintenance that forms the majority of issues dealt with inside a maintenance plan. This is because the unpredictable nature of the point of occurrence means that a reactive maintenance plan is restricted to providing funds to pay for reactive maintenance and facilities to enable an appropriate level of reaction. The planned maintenance category can be divided in to cyclical maintenance, that is, the regular periodical servicing of heating equipment, or preventative, that is, the replacement of a window before age renders it a security threat.

\section{ESTABLISHING THE DESIGN LIFE OF THE SUBJECT BUILDING}

The first stage in formulating a maintenance plan is to establish the design life of the building. This is an estimate of the period that the building will be expected to perform 


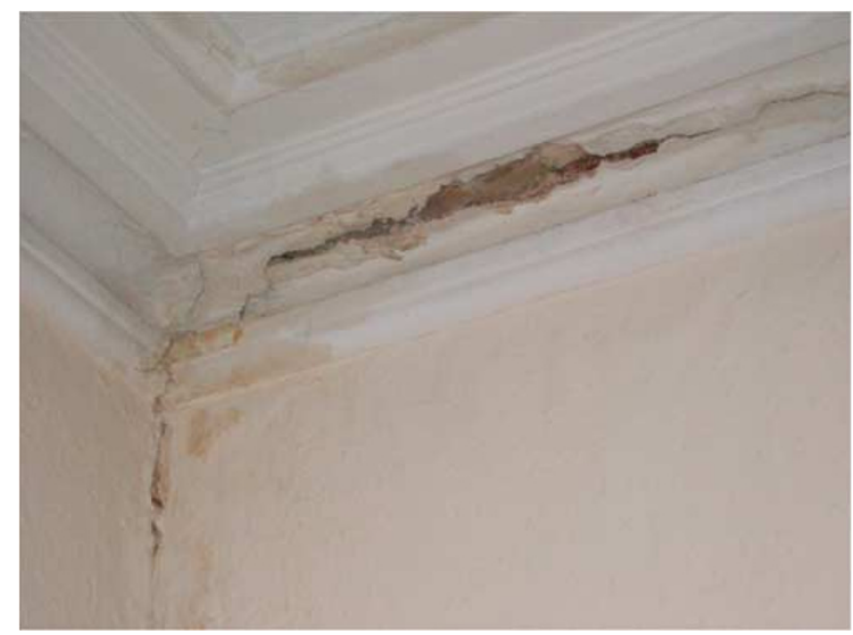

Figure I: Plaster damage due to water ingress, possibly due to a failure in cyclical maintenance, but now requiring reactive action.

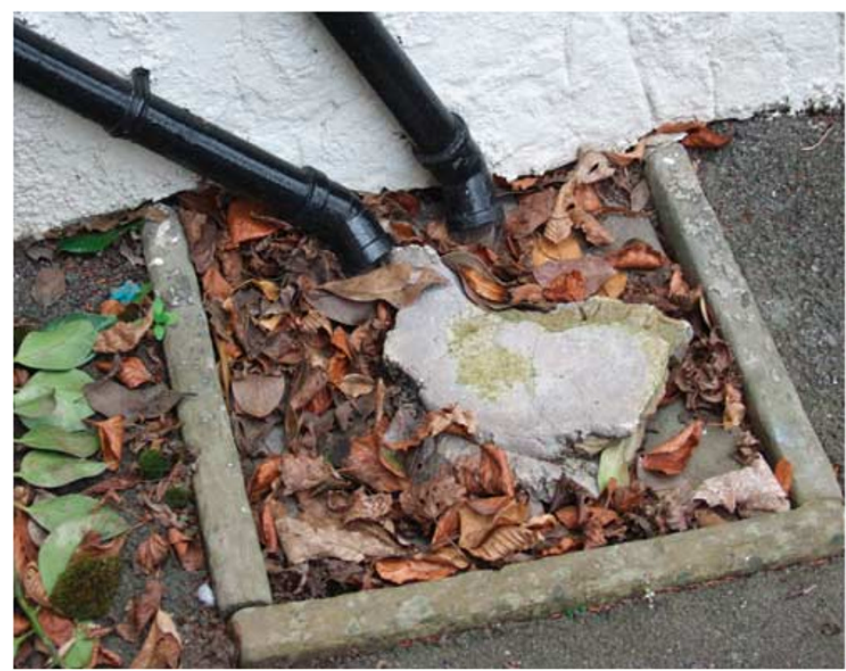

Figure 2: Cleaning of rainwater goods and drains: an example of a typical cyclical maintenance task.

its function. This estimate would be based upon building type, age, usage and user details. There are tables available to categorise buildings from temporary where design life years may be expressed in single figures to the three-figure design lives for some, long-term, civic buildings (British Standards Institution (BSI), 1999). The purpose of establishing this design life figure as a starting point is that it is pivotal to any valid maintenance plan, that is, windows in a short life building may be expected to last the duration of that life, whereas windows in a long life designated building may need replacing several times during that design life period. Predictive window replacement would form a part of a maintenance plan for the latter, but not at all for the former. Any planned general window maintenance may be more proactive on the latter building in which as a reaction to high replacement costs, service life could be extended by means of regular maintenance, rather than the former in which service life may, with minimal maintenance, sit comfortably within the building's design life period. 


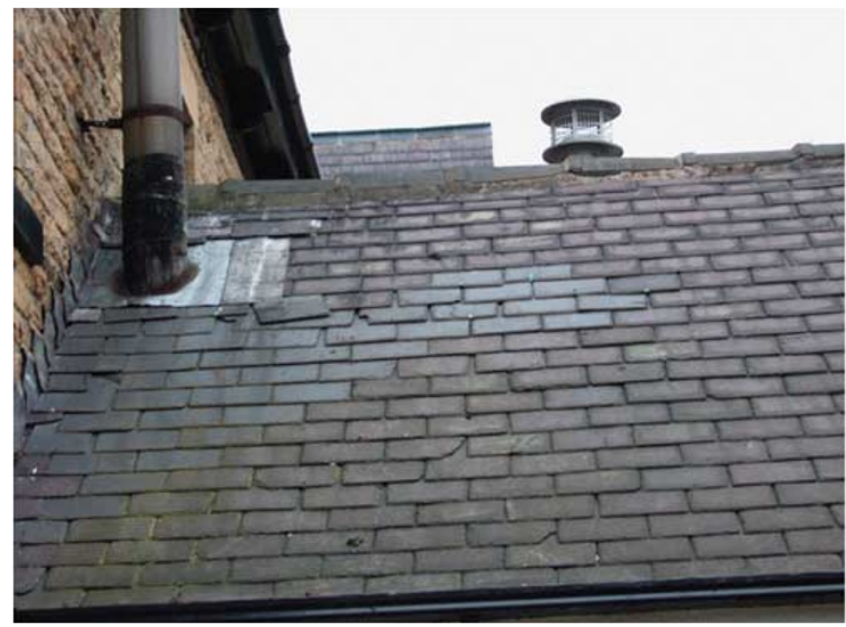

Figure 3: Widespread slipping slates, failing mortar beds and deteriorating flashings: evidence of a possible need for planned future roof covering replacement.

\section{LIFELONG, MAINTAINABLE OR REPLACEABLE}

When undertaking a maintenance plan it is essential to establish the building components requiring maintenance. A building is the sum of many parts; however, each part has different durability and maintenance characteristics. It is essential that the characteristics of each component is analysed in the context of the design life of the building. Some components like foundations would be expected to last for the design life of any building. Other components may be lifelong in the context of short-term or medium-term buildings, but would require replacement in a long-term building. Hence the next maintenance planning task would be identification of those components that will require replacement inside of the predicted design life period. This would be followed by identification of those components that require maintenance, either in order to ensure they last the life of the building or to extend the period before the advent of an inevitable replacement point. Hence analysis of components should identify within the building's design life which components are lifelong, requiring replacement, maintainable or any combination of these other than replaceable and lifelong. This will identify the components to be included in cyclical maintenance tasks, the components that need to be assessed for just-in-time replacement and those for which maintenance is undertaken purely on a reactive-only basis.

\section{ASSESSMENT OF DURABILITY AND SERVICE LIFE}

Having sub-divided the building into its components, and decided upon what requires being included in cyclical maintenance and what requires predictive replacement, it is essential to understand the durability limits of each component or the predicted service life of a manufactured component. This is effectively how long a component will give acceptable levels of service before it needs maintenance or replacement. Once again these periods are very much linked to the design life of the building. Data on durability can be gained from the building's historical data, scientific test data, manufacturer's data or available published durability information. Clearly the former taken from previous performance on the subject building is perhaps the most valid, which stresses the need for rigorous record keeping in the maintenance process, again an issue of maintenance operation that sits outside the remit of this piece. 


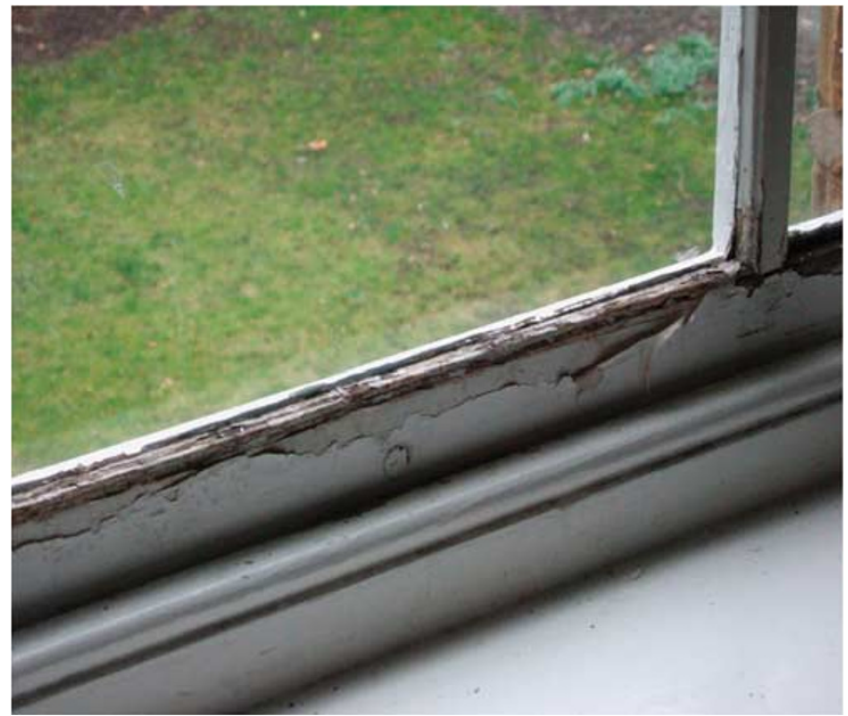

Figure 4: Failure to maintain the paintwork has led to exposure and decay in the timber, thus accelerating the replacement date: a costly repair.

When assessing durability, particularly by not using historical data, patterns of usage need to be established. Many components fail directly through use, and as such some components could fail up to three times quicker during the 24 hours usage patterns rather than under an 8-hours-per-day usage pattern. The reverse could however be true if usage patterns are very low and the building spends long periods unused, unheated and unventilated. Changes in usage patterns can destroy the validity of an existing maintenance plan and need to be factored in at an early stage of the change. Climatic conditions, inherent defects and design features in the building as well as user habits can change design durability data in a real life situation. Perhaps however of greatest importance is the perception of the building owners, clients, in respect of the point that performance is perceived as becoming unacceptable. These variables, which require to be factored in for a maintenance plan to be truly bespoke, are vital in the decision-making process. This can be known as the decision tree process, by which durability limits, and subsequently, maintenance and replacement durations are extended or decreased in reaction to user and usage patterns, exceptional physical conditions and client perception, in a tree diagram format (BSI, 1999), leading to an inevitable totally bespoke set of decisions.

\section{CONSEQUENCE OF LOSS OF PERFORMANCE}

Finally, maintenance is mostly an economic function. The reasons for maintenance tend ultimately to lead back to issues such as monitory losses through customer dissatisfaction, avoidance of statutory redress through failure to meet a legal duty of care and regulatory standards, avoidance of larger replacement costs, avoidance of production down time or maintenance of asset values. In light of this commercial and legal consideration, a final assessment of individual maintenance tasks in terms of the impact of the assessed component falling below that critical point, where performance becomes unacceptable, is required. This takes the form of assessment of the consequence of such a fall. Such a performance failure may lead to potential loss of life or injury, a potential hazard to health, a costly consequential repair (Figure 4), an interruption to 


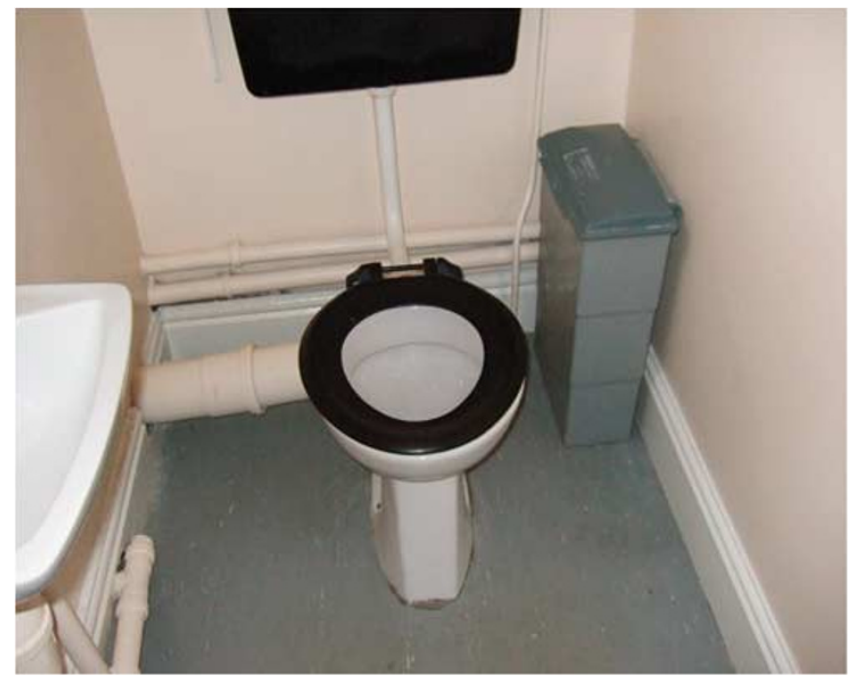

Figure 5: Toilet missing its cover, would a client perceive this as being a still acceptable performance, due for maintenance with a new seat or a unit due for replacement with a modern style of fitting.

building usage, compromised building security, compromised statutory compliance or any other client perceived detraction (Figure 5). The usual method of undertaking this assessment is by using a prioritised list of consequences (BSI, 2000, Part 1). This list also would be bespoked in importance to the perceptions of the specific client. A bank would be more likely to rate compromised security higher than a less asset-rich building user. The consequence rating for a potential component failure may accelerate or reduce previously made decisions on maintenance patterns

\section{CONCLUSION}

Maintenance planning is a client- and building-focused operation. Finding two buildings and clients with the exact same physical conditions, usage requirements and commercial perceptions would be a difficult process. A truly effective maintenance plan needs to be bespoked to the requirements of a specific client, the building, any exceptional physical site conditions, usage patterns and the predicted design life period for the building. A one size fits all spread sheet based approach to maintenance planning is, in the author's view, not a truly effective tool. This would appear to be a view advocated by the BSI whose original standard for maintenance planning BS7543 (1992), and its replacement code of practice ISO 15686-1 (2000), are both still invaluable guidance to the maintenance planner, looking for the elements required to produce that effective bespoke maintenance plan.

\section{REFERENCES}

British Standards Institution. (1999) BS7543:1992 Guide to Durability of Buildings and Building Elements, Products and Components (Including 1998 Amendment). London: BSI Publications, ISBN: 0-580-20870-0. British Standards Institution. (2000) ISO15686:2000 Buildings and Constructed Assets Service Life Planning. London: BSI Publications, ISBN 0-580-3696-8. 